\title{
Bonamia exitiosa in farmed native oysters Ostrea angasi in Australia: optimal epidemiological qPCR cut-point and clinical disease risk factors
}

\author{
T. L. Bradley ${ }^{1, *}$, J. A. Mercer ${ }^{2}$, J. D. Humphrey ${ }^{3}$, N. J. G. Moody ${ }^{4}$, J. C. Hunnam ${ }^{1}$ \\ ${ }^{1}$ Department of Jobs, Precincts and Regions, Mickleham Road, Attwood, Victoria 3049, Australia \\ ${ }^{2}$ Victorian Fisheries Authority, Bellarine Highway, Queenscliff, Victoria 3225, Australia \\ ${ }^{3}$ Panaquatic Health Solutions 3/814 Glenferrie Rd, Hawthorn, Victoria 3122, Australia \\ ${ }^{4}$ Australian Animal Health Laboratory (AAHL), Commonwealth Scientific and Industrial Research Organisation (CSIRO), \\ Portarlington Road, East Geelong, Victoria 3220, Australia
}

\begin{abstract}
Bonamiosis has developed as a problem in Australian native oysters Ostrea angasi since the parasite Bonamia spp. was first detected in Port Phillip Bay, Victoria, in the early 1990s. At that time, large-scale mortalities in both farmed and wild oysters saw the demise of the pilot native oyster culture industry. More recent attempts to farm the species resulted in subclinical infections that progressed over time to clinical disease. The aim of this work was to establish what environmental factors result in the clinical manifestation of disease; determine the diagnostic sensitivity and diagnostic specificity of histopathological examination and a quantitative polymerase chain reaction (qPCR) test for the diagnosis of $B$. exitiosa infection in clinically diseased farmed native oysters; and calculate the optimal qPCR threshold cycle $\left(C_{\mathrm{T}}\right)$ epidemiological cut-point for classification of positive and negative cases. After applying a range of stressors to tank-held oysters, results indicated a 58\% increased risk (95\% CI: 16\%, 99\%) of a Bonamia-infected oyster dying if the oyster was held at a higher temperature $(p=0.048)$. Starving and tumbling oysters, in isolation, was not significantly associated with clinical bonamiosis, but a Bonamia-infected oyster was at the greatest risk of death when increased water temperature was combined with both starvation and increased motion $(\mathrm{p}=0.02$; odds ratio $=3.47$ ). The diagnostic sensitivity and specificity of the World Organisation for Animal Health qPCR protocol were calculated for increasing $C_{\mathrm{T}}$ value cut-points from $\leq 25$ to $\leq 40$, with an optimal cut-point identified at $\leq 34.5$ (specificity: 92.2 ; 95\% posterior credible intervals [PCI]: 76.2, 99.8; Sensitivity: 93.5; 95\% PCI: 84.7, 99.1).
\end{abstract}

KEY WORDS: Australia $\cdot$ Native oysters $\cdot$ Bonamia exitiosa $\cdot$ Diagnosis $\cdot$ Risk factors

\section{INTRODUCTION}

After extensive dredging of native oyster Ostrea angasi beds exhausted wild supplies in bays and inlets around Victoria, Australia, in the 1800s and early 1900s, there were several attempts to farm this species in Port Phillip Bay (Nell 2001). However, devastation of early farming attempts by a parasite belonging to the genus Bonamia in the early 1990s

${ }^{*}$ Corresponding author:

tracey.bradley@agriculture.vic.gov.au resulted in the closure of native oyster farms in Victoria (Hine \& Jones 1994). Despite this early setback, interest in native oyster culture remains strong in south-east Australia in response to the prospect of profitable domestic and international markets. The native oysters also provide an alternative to Pacific oyster Crassostrea gigas monocultures that are susceptible to Ostreid herpesvirus type 1 microvariant (OsHV-1 $\mu$ var). In 2011, a commercial

() The Crown 2020. Open Access under Creative Commons by Attribution Licence. Use, distribution and reproduction are unrestricted. Authors and original publication must be credited. 
Victorian hatchery began producing native oyster spat which were grown out in existing shellfish leases in Port Phillip Bay. By 2015, there were a number of small farm operations in Port Phillip Bay and Western Port.

Bonamiosis is an infectious disease caused by haplosporidian parasites of the genus Bonamia, with the species in Australian native oysters confirmed as B. exitiosa (OIE 2016). The species B. ostreae, although prevalent in much of the world and more recently in New Zealand, is considered exotic to Australia. While Bonamia can be transmitted directly between individual oysters, this pathogen is also suspected of being carried passively on currents between oyster beds (OIE 2019). Surveys have found Bonamia spp. in native oysters off the coast of the Australian states of Victoria, Tasmania, Western Australia and New South Wales (Handlinger et al. 1999) and in Pacific oysters in South Australia (Buss et al. 2019). B. exitiosa is now considered an enzootic parasite of native oysters in Victorian waters.

Bonamia is a small protozoan parasite that infects the haemocytes of affected oysters, with overwhelming numbers of parasites resulting in oyster death (OIE 2019). This parasite has caused catastrophic mortalities internationally, predominantly in members of the family Ostreidae in both aquaculture and wild fisheries (Engelsma et al. 2014). There has been some speculation on the distribution of $B$. exitiosa within the oyster; it has been proposed that infection rarely becomes systemic in Australian native oysters, unlike infections recorded in other countries (Corbeil et al. 2009). This has important ramifications for the ability of different diagnostic tests to detect the presence of these parasites. It has been postulated that the sensitivity of the traditional gold standard diagnostic test (OIE 2019) of histopathological examination may be lower in native oysters sourced from Australia versus other locations.

The outcome of quantitative PCR (qPCR) tests, such as that used to detect $B$. exitiosa infection in native oysters, is continuous, and the distribution of threshold cycle $\left(C_{\mathrm{T}}\right)$ values are generally nonnormal (Burns \& Valdivia 2008). A $C_{\mathrm{T}}$ value cutpoint, above which a test would be considered false, is defined based on utilising either an analytical or epidemiological approach (Caraguel et al. 2011). An analytical approach develops a $C_{\mathrm{T}}$ value cut-point based on criteria gathered during assay development. In contrast, an epidemiological $C_{\mathrm{T}}$ value cut-point is developed based on the probability or cost of a false test result. Calculation of an epidemiological cut-off versus use of an analytical cut-off has been increasingly applied in recent years to reduce the probability of, and costs associated with, misclassification, most typically related to terrestrial animal diseases (Vandenbussche et al. 2008, Mahmmod et al. 2013, Nielsen et al. 2015). There are relatively few qPCR tests applied to aquatic diseases where an epidemiological $C_{\mathrm{T}}$ value cut-point has been calculated, and there is no published cut-point data for $B$. exitiosa.

Bonamiosis is enzootic in native oysters in Victorian waters. Therefore, the application of an epidemiological cut-point is appropriate, as the focus of testing in this circumstance is on minimising the overall impact of the disease on farmers (rather than eradication). However, this methodology would not be appropriate during surveillance for an exotic disease, for example, where a false negative diagnosis (that could not be further confirmed) has significant ramifications.

Annual monitoring of Victorian native oyster farms by qPCR and histopathological examination for infection with Bonamia spp. began in 2011. Infection in apparently healthy oysters was detected 2 yr later and progressively increased in subclinical prevalence, culminating in a clinical outbreak of bonamiosis at one site associated with high mortalities (OIE 2016). Sequencing determined that this outbreak was due to $B$. exitiosa. Subclinical infection was detected by qPCR surveillance in wild native oysters in Port Phillip Bay and on some farm sites, but did not progress to clinical expression of disease. Given the similar provenance of source stock and history of bonamiosis in Victorian waters, the issue of why some infected farm sites progress to clinical disease where others remain healthy is of interest.

To investigate this question, identification of risk factors that may trigger clinical disease/death due to $B$. exitiosa infection in Australian O. angasi, including source location, oyster size and water temperature, was undertaken. It is presumed that where these factors are known and can be manipulated, management to prevent epizootics of native oysters caused by bonamiosis may be possible. The primary objectives of this study were to (1) determine the diagnostic sensitivity and specificity of histopathological examination and a qPCR test for the diagnosis of $B$. exitiosa infection in clinically diseased farmed native oysters, assuming a lack of a 'gold standard' test; (2) calculate the optimal qPCR $C_{\mathrm{T}}$ epidemiological cut-point for classification of positive and negative cases; and (3) determine risk factors significantly associated with the conversion from subclinical to clinical bonamiosis of native oysters held in a controlled environment. 


\section{MATERIALS AND METHODS}

\subsection{Oyster selection}

Trial oysters were sourced from established farms in 3 distinct geographic locations in Port Phillip Bay and Western Port, Victoria (Fig. 1). Farms were selected based on a known history of testing for Bonamia exitiosa. Population 1 oysters were sourced from a coastal lease located on the western side of Port Phillip Bay $\left(38^{\circ} 6.2^{\prime} \mathrm{S}, 144^{\circ} 41.3^{\prime} \mathrm{E}\right)$. Annual surveillance for Bonamia spp. in oysters from this site was conducted by histopathology and/or qPCR from 2011 until a major epizootic in 2015 when mortalities reached approximately $80 \%$ (T. Bradley unpubl. data). Population 2 oysters were derived from a landbased hatchery facility in Western Port $\left(38^{\circ} 28.1^{\prime} \mathrm{S}\right.$, $\left.145^{\circ} 2.3^{\prime} \mathrm{E}\right)$ where Bonamia spp. infection had been diagnosed through annual surveillance, but there was no evidence of deaths due to clinical bonamiosis. Oysters within Population 3, from the eastern side of Port Phillip Bay $\left(38^{\circ} 14.2^{\prime} \mathrm{S}, 145^{\circ} 0.5^{\prime} \mathrm{E}\right)$ had been tested for Bonamia spp. annually with universally negative results and a farmer-reported base mortality rate of approximately $2-3 \%$.

\subsection{Trial design: Trial 1 (February 2016)}

Independent, controlled tank trials were conducted at the Victorian Fisheries Authority, Queenscliff, Vic-

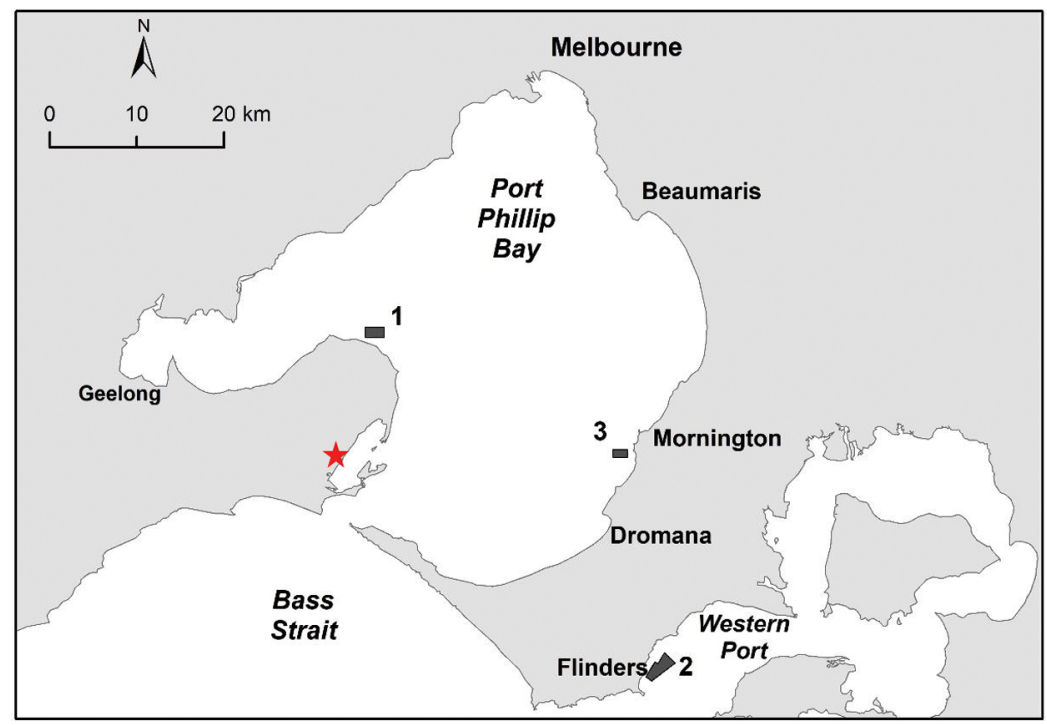

Fig. 1. Geographic location of source populations (1,2 and 3) for 2 tank trials assessing risk factors for clinical bonamiosis in farmed native oysters (inset: Victoria, Australia, with location of Port Phillip Bay and Western Port). Red star: location of the research facility toria. The units of interest were the individual native oysters Ostrea angasi. Live farmed oysters were selected from a range of cages deployed on 2 long lines within Population 1 and immediately graded, resulting in a final trial population of 240 oysters with a mean size of $66.7 \pm 0.7 \mathrm{~mm}$. Oysters were acclimated at the trial facility for approximately $3 \mathrm{~d}_{i} 6$ oysters died prior to the trial commencement. There was no tissue recovered from these oysters. Ten oysters were held in modified SEAPA ${ }^{\circledR}$ cages within each of 24 individual $100 \mathrm{l}$ tanks for the trial period of $56 \mathrm{~d}$.

Each possible combination of 3 risk factors namely, water temperature (i.e. warm versus ambient), water motion (none versus oscillation) and nutrition (starved versus adequate nutrition) - were applied across multiple tanks in a $2^{3}$ (i.e. $2 \times 2 \times 2$ ) factorial design nested in a randomized control block design (RCBD). Due to a lack of adequate space at the facility, a single replicate negative control tank was applied, with 10 oysters sourced from Population 3. A single positive control tank was also applied, with 10 oysters sourced from Population 1 held at ambient temperature and with adequate nutrition for the duration of the trial. These oysters were inspected first, had minimal handling and were kept in the same room as the rest of the stock.

Ambient seawater (filtered to $30 \mu \mathrm{m}$ ) was supplied to the tanks from Port Phillip Bay at a flow rate of $600 \mathrm{ml} \mathrm{min}^{-1}$. 'Warm' water was heated by an Aquahort heat pump (Model AH2000HO). Temperatures were determined by 4 in-tank thermometers and recorded daily in each of the ambient and heated tanks. The mean ambient temperature was $18.2 \pm 0.3^{\circ} \mathrm{C}$ mean heated temperature was $22.9 \pm 0.4^{\circ} \mathrm{C}$. Where applicable, oysters were fed

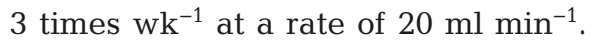
The feed was algae harvested from a Seawater Continuous Algal Production System stored in 50001 openair tanks enclosed in a greenhouse environment. The species composition was approximately 50\% Chaetoceros muelleri, 27\% Pavlova lutheri and $23 \%$ Tisochrysis lutea. All species stocks were originally sourced from the Australian National Algal Supply Service at the Commonwealth Scientific and Industrial Research Organisation (CSIRO) in Tasmania. All species were fed on a f2 nutrient media. 'Starved' oysters were not fed. Tumbling was simulated using a SMI 
multi-tube vortexer oscillator (Analytical instruments) at $1700 \mathrm{rpm}$, with each group of oysters being oscillated in a group-specific container for $60 \mathrm{~s}$ every second day. All tanks were cleaned every second day, and strict biosecurity was maintained between tanks.

\subsection{Trial design: Trial 2 (March 2017)}

Independent, controlled tank trials were conducted at the same facility as Trial 1. Similar to Trial 1, each possible combination of 3 risk factors were applied in triplicate in a $2^{3}$ factorial design nested in a RCBD; namely, source (Population 1 vs. Population 2), oyster size (small, 52-85 cm vs. large, 74-154 cm) and stress (high temperature and starved vs. ambient temperature and adequately fed; as for Trial 1) for a total trial period of $83 \mathrm{~d}$. Oscillation was not included as a stressor in Trial 2 as it was not independently associated with mortalities in Trial 1, as well as for logistical reasons. Trial 2 oysters were acclimated for $7 \mathrm{~d}$; 12 oysters had died by the start of the trial. A total of 10 sampled oysters were held within modified cages in each of 24 individual 1001 tanks for the duration of the trial. Additionally, 10 oysters from Population 3 were held in each of 4 negative control tanks.

During both trials, oysters were checked at least once daily by a competent technician to monitor and collect tissue from dead oysters. Checking involved observing whether oysters were open (and feeding). If there was concern about the live/dead status of the oyster, the oyster was tapped with a knife and an attempt made to gently pry open to gauge resistance. However, despite consistent monitoring, tissue could not always be recovered as tissue degradation was rapid within dead oysters. All other features of the tank setup, such as feeding and water temperature schedules, were consistent between the 2 trials.

\subsection{Diagnostic tests}

During Trial 1, tissue from all trial oysters were, where possible, collected and tested for Bonamia spp. using a qPCR. During Trial 2, tissues from all trial oysters were, where possible, collected for both qPCR and histopathological examination.

All qPCR testing was undertaken at CSIRO in Geelong, Victoria. A small piece of gill was taken from each oyster and fixed in 95\% ethanol as per World Organisation for Animal Health recommendations
(OIE 2019). Each sample was tested in duplicate using the Bonamia spp. qPCR described by Corbeil et al. (2009), with the 18S rRNA qPCR applied as the positive extraction control. While this assay detects both $B$. exitiosa and $B$. ostreae, sequencing of amplicons confirmed the identity of the Bonamia spp. as $B$. exitiosa, with all amplicons sequenced from all positive submissions sharing $>99 \%$ nucleotide similarity with $B$. exitiosa reference sequences. An analytical cut-point was applied where all samples that did not produce a $C_{\mathrm{T}}$ value after 45 cycles, using a threshold of -0.1 , were considered negative. The mean of $2 C_{\mathrm{T}}$ values was used where both wells were positive. An indeterminate qPCR result was applied when one of the duplicates produced a positive result and the other a negative result, indicating that the level of target in this sample was close to the limit of detection for this test.

For histopathological assessment, one or more section(s) of tissue were taken from each oyster, including the mantle, gills, digestive gland and/or gonad and fixed in $10 \%$ buffered formalin for a minimum of $24 \mathrm{~h}$ (OIE 2019). Where the oyster was sufficiently small or limited tissue remained, the whole oyster was placed in fixative after the PCR sample was removed. A $3 \mathrm{~mm}$ wide section from each available tissue was trimmed, embedded in paraffin and $5 \mu \mathrm{m}$ sections were cut and stained in haematoxylin and eosin using standard methods (Centre for AgriBioscience). All histopathological examination of slides was undertaken by the same experienced, senior pathologist. Sections for examination were selected at random and assessed with no reference to observations of other sections sourced from the same batch of oysters.

Each section was scanned at low power $(40 \times)$ and subsequently, each tissue was examined at higher power $(100 \times, 400 \times)$ to determine the nature and intensity of inflammatory and degenerative changes and presence or absence of $B$. exitiosa. Areas were targeted where focal or generalised inflammatory changes were observed in specific tissues, using oil immersion $(1000 \times)$ as required. Identification of $B$. exitiosa followed the Australia and New Zealand Standard Diagnostic Procedure (Corbeil et al. 2006). The occurrence, distribution and number of organisms observed in tissues was recorded in a semiquantitative manner based on previous work by Diggles et al. (2003) and Johnston (1992), but with further refinement.

In several cases, cells that were not morphologically typical of $B$. exitiosa, possibly due to autolysis or degradation, but which could not be absolutely ex- 
cluded as being B. exitiosa, were assessed as equivocal $( \pm)$. These cases were excluded from further analysis.

\subsection{Descriptive analysis}

Data were recorded in a spreadsheet using Microsoft Excel 2016. An oyster-level binary score of Bonamia-positive, based on histopathological examination, was assigned even if only a single or occasional B. exitiosa (Category 1) was visualised in at least one tissue section.

\subsection{Latent class analyses: estimation of diagnostic sensitivity and specificity}

The performance of histopathological examination and qPCR was assessed using a latent class model with a Bayesian approach, with data derived from Trial 2 (Branscum et al. 2005). This allowed calculation of the diagnostic sensitivity (DSe) and specificity (DSp) of the 2 tests, as well as the prevalence in the 2 populations under a number of assumptions. It was assumed that the 2 tests were conditionally independent (i.e. the DSe and DSp of qPCR were independent of the outcome of histopathological examination when used to test the same individuals) and that the proportion of truly infected oysters differed between Populations 1 and 2. It was also assumed that diagnostic test properties were constant across both populations.

Within a Bayesian analysis, prior distributions of all parameters, including DSe, DSp and prevalence, must be specified and reflect known information. The prior distributions for the DSe and DSp for histopathological examination and prevalence of $B$. exitiosa in Populations 1 and 2 were modelled as Beta( $a$, $b$ ) distributions. The specific shape parameters $a$ and $b$ were derived based on the most likely value (mode) and $n^{\text {th }}$ percentile of the values found in the literature and based on expert opinion (Table 1). Prior information on the DSe and DSp for the qPCR tests were modelled using the $\operatorname{Beta}(1,1)$ distribution which is uniform for the interval between 0 and 1 (i.e. an uninformative prior). All Beta prior distributions were parameterised using 'epi.betabuster' in $\mathrm{R}$ version 3.5.0 (R Core Team 2018, Stevenson et al. 2019).

Histopathological examination is recommended as the surveillance method of choice in regions exclusively infected with $B$. exitiosa (OIE 2019). When compared with a combination of conventional PCR and in situ hybridisation, histopathological examination showed a DSe of $44.0 \%$ and DSp of $100.0 \%$ (listed here as $99.99 \%$ ) for the diagnosis of $B$. exitiosa in New Zealand flat oysters $O$. chilensis (Diggles et al. 2003). Both PCR (conventional and Taqman) and histopathology are recommended for presumptive diagnosis of $B$. exitiosa by the World Organisation for Animal Health (OIE 2019). Although a PCR for B. exitiosa in $O$. chilensis has been previously validated with a diagnostic DSe of $88.2 \%$ and a DSp of $36.4 \%$ (relative to a combination of histology and heart imprints) (Diggles et al. 2003), the qPCR used in this paper was developed by CSIRO and has not been formally validated using an epidemiological cut-point. The prevalence of $B$. exitiosa infection in Populations 1 and 2 was estimated based on the proportion of non-stressed oysters diagnosed using histopathological examination at the end of Trial 2.

The analysis was implemented in OpenBUGS version 3.2.3, using a Markov chain Monte Carlo sampling algorithm to obtain a Monte Carlo sample from the posterior distribution (Thomas et al. 2006). The first 10000 iterations were discarded as a burn-in to allow convergence and the successive 40000 iterations used for the posterior inference. Convergence was assessed by visual inspection of the time-series plots of selected variables, as well as Gelman-Rubin diagnostic plots using 3 sample chains with different starting values (Toft et al. 2007). Posterior inference

Table 1. Distributions for prior information of known variables for histopathological examination of Bonamia exitiosa in Australian native oysters. DSe: diagnostic sensitivity; DSp: diagnostic specificity; histo: histopathological examination; Prev: prevalence; P: population

\begin{tabular}{|lccccc|}
\hline Parameter & $\begin{array}{c}\text { Most likely } \\
\text { value (mode) }\end{array}$ & Percentile & $\begin{array}{c}\text { Percentile's } \\
\text { value }\end{array}$ & Beta distribution & Reference \\
\hline DSp-histo & 0.999 & 20 & 0.90 & Beta(15.47, 1.01) & Diggles et al. (2003) \\
DSe-histo & 0.440 & 20 & 0.35 & Beta(8.57, 10.64) & Diggles et al. (2003) \\
Prev-P1 & 0.172 & 20 & 0.10 & Beta(1.73, 4.50) & Trial 2 \\
Prev-P2 & 0.390 & 20 & 0.30 & Beta(6.59, 9.74) & Trial 2 \\
\hline
\end{tabular}


was performed by calculating the median and 95\% posterior credible intervals $\left(95 \% \mathrm{PCI}_{\text {; the }}\right.$ Bayesian analog of a $95 \%$ CI) of the DSe and DSp of the 2 tests and the prevalence in Populations 1 and 2.

To investigate whether the specified prior knowledge would have affected the parameter posterior estimates, the analysis was repeated using uninformative priors for all parameters, as well as different levels of certainty in the definition of priors for DSe and DSp of qPCR and histopathological examination. The models with different priors were compared using the deviance information criteria (DIC), with the best model reported (i.e. smallest DIC) (Spiegelhalter et al. 2002).

To determine the epidemiological $C_{\mathrm{T}}$ value cutpoint of the CSIRO qPCR, separate Bayesian analyses were performed with an increase from $\leq 25$ to $\leq 40$, in 1 value increments, with histopathological examination and prevalence data kept constant. The maximum cut-point was set at 40 , as there was no further change in DSe or DSp above this value. A 2-graph receiver operating curve plot (sensitivity-specificity plot) was constructed to illustrate the change in qPCR sensitivity and specificity with a decrease in $C_{\mathrm{T}}$ value cut-point, with the optimal epidemiological cut-point defined as the point at which the DSe and DSp crossed (i.e. both parameters were maximised).

Oysters in Trial 1 and Trial 2 were then categorised into 4 subsets based on a qPCR $C_{\mathrm{T}}$ value at or below the optimal cut-point and whether the oyster had died by trial end (Table 2).

\subsection{Logistic regression analysis: risk factors for clinical bonamiosis}

Risk factors with a p-value of $<0.20$ in univariable logistic regression were evaluated using generalised linear mixed models within the 'nlme' package in RStudio (RStudio Team 2018), with separate

Table 2. Parameters for categorisation of native oysters, based on an optimal epidemiological quantitative PCR (qPCR) threshold cycle $\left(C_{\mathrm{T}}\right)$ value cut-point and dead/alive status at trial end

\begin{tabular}{|c|c|c|}
\hline Category & qPCR $C_{\mathrm{T}}$ value & $\begin{array}{l}\text { Dead/alive } \\
\text { at trial end }\end{array}$ \\
\hline Clinical bonamiosis & soptimal cut-point & Dead \\
\hline Subclinical bonamiosis & $\leq$ optimal cut-point & Alive \\
\hline $\begin{array}{l}\text { Death due to reason other } \\
\text { than Bonamia infection }\end{array}$ & >optimal cut-point & Dead \\
\hline Non-infected & >optimal cut-point & Alive \\
\hline
\end{tabular}

models created for Trial 1 and Trial 2. To determine risk factors for the development of clinical bonamiosis, oysters categorised with 'clinical bonamiosis' (Table 2) were compared against oysters with 'subclinical bonamiosis'. Oysters in other categories were excluded from further analyses. Model building used manual backwards elimination, with all eliminated factors re-evaluated for confounding effects and biologically meaningful pairwise interactions assessed between the final model variables. An effect of clustering at the tank level was evaluated in the final model using tank as a random effect. Model fit diagnostics were evaluated (Lemeshow \& Hosmer 1982). Results are presented as odds ratios (ORs) and significance indicated using $\mathrm{p}$-values, with a statistical significance level set at $\alpha=0.05$.

\subsection{Survival analysis: risk factors for time to oyster death}

Median survival time of Bonamia-positive oysters to death (clinical bonamiosis) was estimated using the Kaplan-Meier method along with finite sample pointwise confidence intervals and 95\% Hall-Werner confidence bands (Hall \& Wellner 1980), with differences between categories evaluated by the log-rank test. Explanatory variables with $\mathrm{p}<0.20$ in univariable Cox proportional hazards regression models were assessed using multivariable Cox modelling with robust standard errors calculated to account for within-tank clustering. Model fitting used a manual backward elimination approach with significance level set at $\alpha=0.05$. The proportionality assumption was tested using Schoenfeld and scaled Schoenfeld residuals, and the fit of the final model to the data was checked using Cox-Snell residuals. Results are presented as hazard ratios (HRs) and significance indicated using $p$-values, with statistical significance set at $\alpha=0.05$.

\section{RESULTS}

\subsection{Descriptive analysis}

A total of 490 oysters sourced from Populations 1 and 2 were enrolled across both trials. Of that initial number, 23 (Trial 1) and 8 (Trial 2) oysters died and did not have tissue available for testing by qPCR. At the end of both trials, $29.2 \%$ of the available 459 oysters had a $C_{\mathrm{T}}$ value of $\geq 45.0$ (i.e. classified as negative 
based on this analytical cut-point). The median $C_{\mathrm{T}}$ values of the remaining oysters were 29.8 (Population $1 ; \mathrm{n}=228$ ) and 22.9 (Population 2; $\mathrm{n}=97$ ) (Fig. 2).

Tissues from 7 oysters within Trial 2 were unavailable for histopathological examination. Of the remaining oysters, the majority (222 oysters; $92.5 \%$ ) had 5 or 6 tissue sections (interstitium, stomach, digestive gland, intestine, gills and/or palp) available for examination, with the interstitium and digestive gland most commonly sampled (98.3-99.6\%).

Bonamia exitiosa was observed most commonly and in the highest numbers within haemocytes in the interstitium and the Leydig tissue of the digestive gland and palp and least commonly in the Leydig tissue surrounding the stomach (Fig. 3). Of the 108 oysters diagnosed as Bonamia-positive based on histopathological examination, $80 \%$ were based on examination of the interstitium and/or digestive gland.

Bonamia spp. was observed in 4 or more tissues within $82.9 \%$ of infected dead oysters, compared to $18.9 \%$ of infected live oysters, indicating that systemic dissemination of the parasite throughout an oyster was associated with death.

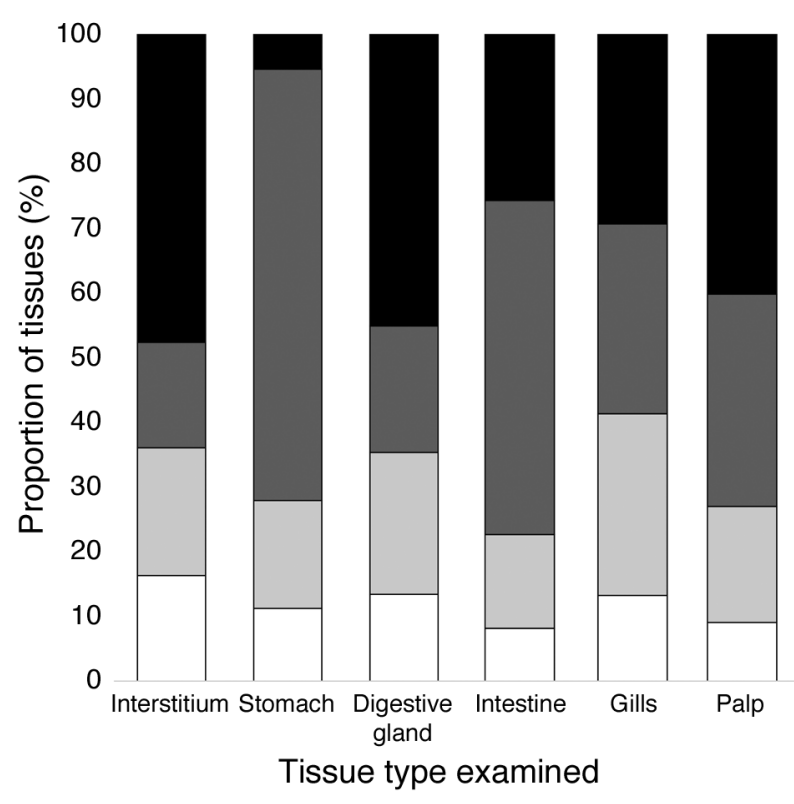

Fig. 3. Proportion of Bonamia-positive tissue sections $(\mathrm{n}=$ 18-86) that had single/occasional (white), low (light grey), medium (dark grey) and high (black) numbers of $B$. exitiosa observed, by tissue type, in farmed native oysters

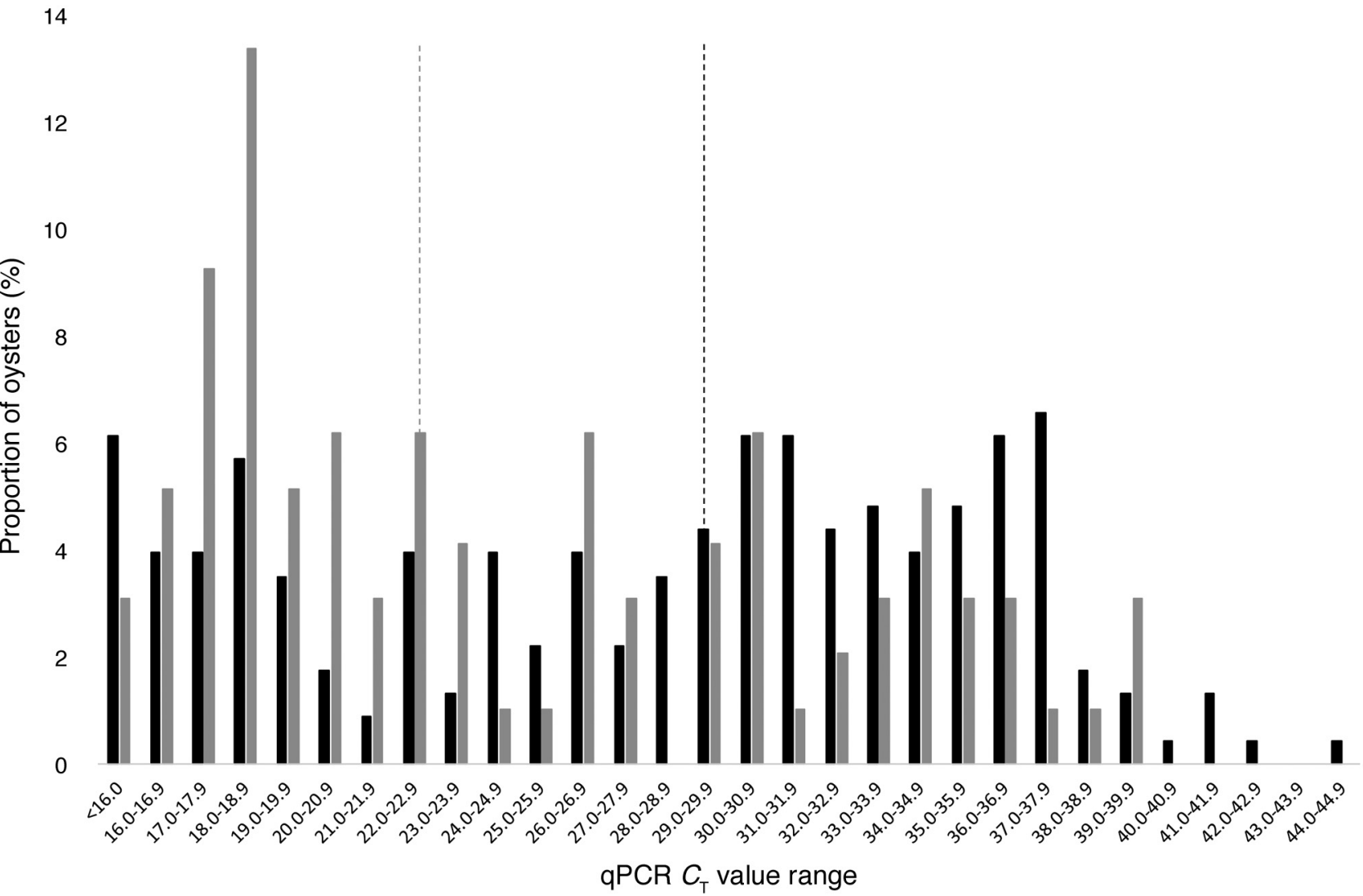

Fig. 2. Proportion of farmed native oysters that were diagnosed with a Bonamia quantitative PCR (qPCR) cycle threshold $\left(C_{\mathrm{T}}\right)$ value $<45.0$, at intervals of 1.0 (dashed line $=$ median $C_{\mathrm{T}}$ value), stratified by source population (Population 1 [n = 228]: black; Population 2 [n =97]: grey). Dashed lines: median $C_{\mathrm{T}}$ values 
In total, 47 of 50 (94.0\%) Population 3 oysters (i.e. negative controls) were alive and Bonamia-negative on qPCR and histopathological examination at the end of the trial period (across Trials 1 and 2). This indicated that the overall tank environment (considered independently of any disease condition and/or stress) did not significantly influence oyster survival during both trials. Two Population 3 oysters were alive at trial end (Trial 2) and were negative on histopathological examination for Bonamia spp., but had qPCR $C_{\mathrm{T}}$ values of 24.7 and 28.0. The one oyster from Population 3 that died during the trial period (Trial 2) was Bonamia-negative on both qPCR and histopathological examination and was in a different tank than the 2 Bonamia-positive Population 3 oysters.

\subsection{Estimation of diagnostic test sensitivity and specificity}

The DSe and DSp of the qPCR were calculated for increasing $C_{\mathrm{T}}$ value cut-points from $\leq 25$ to $\leq 40$, with an optimal cut-point identified at $\leq 34.5$ (DSp: 92.2, 95\% PCI: 76.2, 99.8; DSe: 93.5, 95\% PCI: 84.7, 99.1) (Fig. 4).

The estimated test characteristics of histopathological examination and the qPCR (at optimal epidemiological cut-point of $\leq 34.5$ ) are detailed in Table 3. The sensitivity of qPCR was significantly higher com-

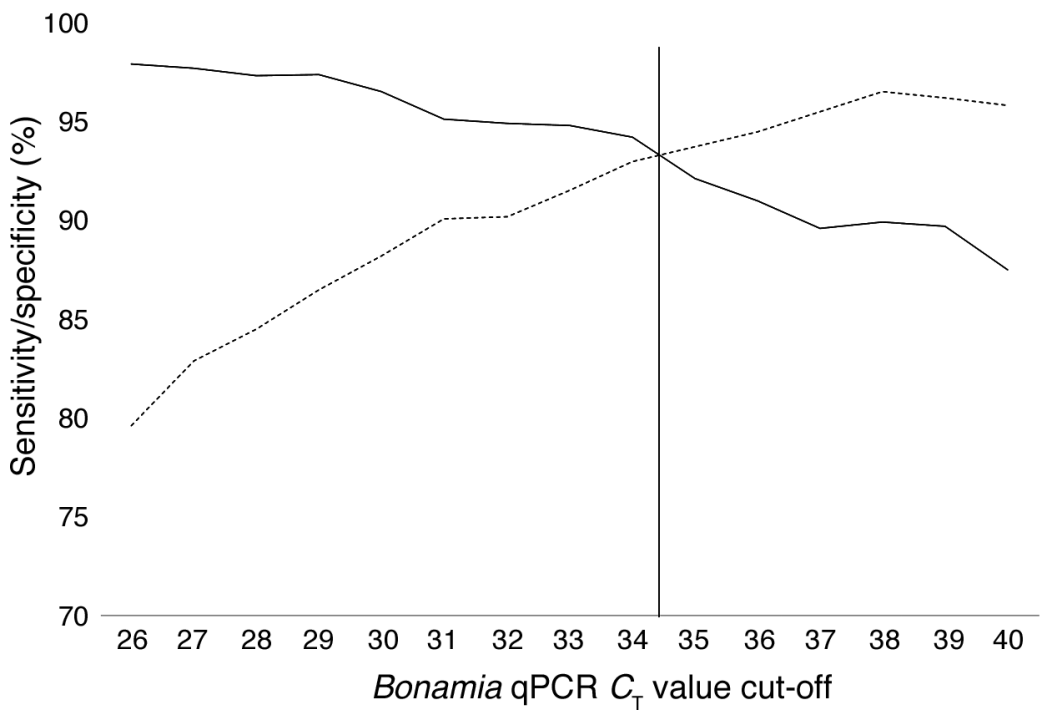

Fig. 4. Two-graph receiver operating characteristic plot (sensitivity-specificity plot) with sensitivity (dashed) and specificity (solid) calculated for increased threshold cycle $\left(C_{\mathrm{T}}\right)$ cut-point values for the Bonamia spp. quantitative polymerase reaction (qPCR) test. Vertical line: sensitivity and specificity equivalent
Table 3. Posterior median and 95\% posterior credible intervals (PCI) of the sensitivity and specificity of quantitative PCR (qPCR) (cut-point $\leq 34.5$ ) and histopathological examination (Histo) in the diagnosis of Bonamia spp. in farmed native oysters, and the estimated prevalence in 2 independent populations

\begin{tabular}{|lccc|}
\hline Parameter & Test/farm & Estimate & $95 \%$ PCI \\
\hline Diagnostic & qPCR & 92.2 & $76.2,99.8$ \\
specificity & Histo & 98.7 & $94.3,99.9$ \\
Diagnostic & qPCR & 93.5 & $84.7,99.1$ \\
sensitivity & Histo & 50.8 & $41.4,62.3$ \\
Prevalence & Population 1 & 37.0 & $26.4,49.3$ \\
& Population 2 & 55.0 & $44.1,67.2$ \\
\hline
\end{tabular}

pared to histopathological examination, while the specificities of both tests were very high (>92.0\%).

\subsection{Risk factors for clinical bonamiosis: Trial 1}

At the end of Trial 1, 118 live oysters (72.3\%) had a qPCR $C_{\mathrm{T}}$ value of $>34.5$ (i.e. were classified as negative based on the epidemiological cut-point). Of the 240 Population 1 oysters, 86 had died (35.8\%) and, of the 63 dead oysters that had tissues available for testing, $17(27.0 \%)$ had a qPCR $C_{\mathrm{T}}$ value of $>34.5$, indicating death due to a reason other than $B$. exitiosa infection. Forty-seven oysters had died with clinical bonamiosis at trial end and 45 oysters were diagnosed with subclinical bonamiosis (Table 4).

There was a 58\% increased risk (95\% CI: $16 \%, 99 \%)$ of a Bonamiainfected oyster dying if the oyster was held at a higher temperature $(\mathrm{p}=$ 0.048) (Table 5). Although starving and tumbling oysters in isolation was not significantly associated with clinical bonamiosis, a Bonamia-infected oyster was at the greatest risk of death when increased water temperature was combined with both starvation and increased motion $(\mathrm{p}=0.02$; $\mathrm{OR}=$ 3.47). At the end of the trial, $24 \%$ of the variation in oyster status (clinical or subclinical bonamiosis) was at the tank level, indicating a proportion of the deaths of Bonamia-infected oysters was associated with withinindividual tank effects as well as stress induced by the risk factors. 
Table 4. Number of farmed Bonamia-positive native oysters $(n=227)$ sourced from Victoria, Australia, (quantitative PCR [qPCR] threshold cycle value $\leq 34.5$ ) after a trial period of $56 \mathrm{~d}$ (Trial 1) and case fatality rate, by risk factors of interest. Numbers in the 'Total' column are those with tissue available for qPCR testing

\begin{tabular}{|c|c|c|c|c|c|c|}
\hline \multirow{2}{*}{$\begin{array}{c}\text { Water }_{\text {temperature }} \\
\text { R }\end{array}$} & \multirow{2}{*}{$\begin{array}{l}\text { Risk factors } \\
\text { Nutrition } \\
\text { e }\end{array}$} & \multirow[b]{2}{*}{$\begin{array}{l}\text { Water } \\
\text { motion }\end{array}$} & \multirow{2}{*}{ Total } & \multicolumn{2}{|c|}{ Bonamia-positive } & \multirow{2}{*}{$\begin{array}{l}\text { Case } \\
\text { fatality } \\
\text { rate }\end{array}$} \\
\hline & & & & $\begin{array}{l}\text { No. (\%) of } \\
\text { oysters }\end{array}$ & $\begin{array}{l}\text { No. of } \\
\text { deaths }\end{array}$ & \\
\hline \multirow[t]{4}{*}{ Hot } & \multirow[t]{2}{*}{ Adequate } & Tumbled & 24 & $5(20.8)$ & 2 & 0.40 \\
\hline & & Still & 27 & $11(40.7)$ & 9 & 0.82 \\
\hline & \multirow[t]{2}{*}{ Starved } & Tumbled & 28 & $22(78.6)$ & 12 & 0.55 \\
\hline & & Still & 28 & $18(64.3)$ & 7 & 0.39 \\
\hline \multirow[t]{5}{*}{ Cold } & \multirow[t]{2}{*}{ Adequate } & Tumbled & 30 & $12(40.0)$ & 8 & 0.67 \\
\hline & & Still & 39 & $11(28.2)$ & 4 & 0.36 \\
\hline & \multirow[t]{3}{*}{ Starved } & Tumbled & 28 & $10(35.7)$ & 3 & 0.30 \\
\hline & & Still & 23 & $3(13.0)$ & 2 & 0.67 \\
\hline & & Total & 227 & $92(40.5)$ & 47 & 0.51 \\
\hline
\end{tabular}

Table 5. Generalised linear mixed model evaluating the significance of associations between potential risk factors and native oyster status (subclinical bonamiosis versus clinical bonamiosis) after $56 \mathrm{~d}$ (Trial 1). $\beta$ : co-efficient; $\mathrm{SE}(\beta)$ : standard error of the co-efficient; OR: odds ratio, LCI/UCI: lower/upper 95\% confidence interval. Statistical significance at $\mathrm{p} \leq 0.05$

\begin{tabular}{|lcccccc|}
\hline Risk factor & $\beta$ & $\mathrm{SE}(\beta)$ & $\mathrm{p}$ & $\mathrm{OR}$ & $\mathrm{LCI}$ & $\mathrm{UCI}$ \\
\hline Starved & 0.30 & 0.32 & 0.36 & 1.35 & 0.72 & 1.99 \\
Hot temperature ('hot') & 0.45 & 0.21 & 0.05 & 1.58 & 1.16 & 1.99 \\
Tumbling motion ('tumbled') & 0.30 & 0.21 & 0.16 & 1.35 & 0.95 & 1.76 \\
Starved $\times$ hot $\times$ tumbled & 1.24 & 0.49 & 0.02 & 3.47 & 2.50 & 4.44 \\
\hline
\end{tabular}

\subsection{Risk factors for clinical bonamiosis: Trial 2}

Of 240 oysters held in 24 study tanks in Trial 2, 4 small oysters in 3 individual tanks did not have tissue available at the end of the study for qPCR and histopathological examination. An additional 4 oysters did not have tissue available for histopathological examination, but were tested using qPCR. At the end of the trial period, 65 live oysters $(41.9 \%)$ had a qPCR $C_{\mathrm{T}}$ value of $>34.5$ (i.e. were non-infected). Eightythree of 240 oysters had died (34.6\%) and, of the 77 dead oysters that had tissues available for testing, $2(2.5 \%)$ had a qPCR $C_{\mathrm{T}}$ value of $>34.5$ indicating death due to a reason other than $B$. exitiosa infection. At trial end, 75 oysters had died with clinical bonamiosis and 90 oysters were diagnosed with subclinical bonamiosis (Table 6).

The mean case fatality rate (i.e. ratio of dead to Bonamia-positive oysters) within the study period was higher in oysters sourced from Population 2 (0.65) than oysters sourced from Population 1 (0.25) (Table 6). Similarly, the population from which Bonamia-positive oysters were sourced was significantly associated with likelihood of death over the trial period, with an $82 \%$ higher risk in Population 2 oysters versus Population 1 (Table 7). However, whether the oyster was stressed was not significantly associated with the risk of a Bonamia-positive oyster dying, when considered in isolation $(p=0.21)$. Although smaller oysters had higher case fatality rates and proportion Bonamia-positive relative to larger oysters where the source and environment were the same (with the exception of unstressed oysters from Population 1), this relationship was non-significant ( $p=0.79$ ) (Table 7). There were also no significant interactions between assessed risk factors $(p \geq 0.44)$. Approximately $17 \%$ of variation in the outcome was associated with the tank in which the oyster was located.

Table 6. Number of native oysters $(n=232)$ sourced from Victoria, Australia, that were Bonamia-positive (quantitative PCR [qPCR] threshold cycle value $\leq 34.5$ ) after a trial period of $83 \mathrm{~d}$ (Trial 2) and case fatality rate, by risk factors of interest. Numbers in the 'Total' column are those with tissue available for qPCR testing

\begin{tabular}{|c|c|c|c|c|c|c|}
\hline \multirow[b]{2}{*}{ Site } & \multirow{2}{*}{$\begin{array}{l}\text { isk factors } \\
\text { Stressed }\end{array}$} & \multirow[b]{2}{*}{$\begin{array}{l}\text { Oyster } \\
\text { size }\end{array}$} & \multirow[t]{2}{*}{ Total } & \multicolumn{2}{|c|}{ Bonamia-positive } & \multirow{2}{*}{$\begin{array}{c}\text { Case } \\
\text { fatality } \\
\text { rate }\end{array}$} \\
\hline & & & & $\begin{array}{c}\text { No. }(\%) \text { of } \\
\text { oysters }\end{array}$ & $\begin{array}{l}\text { No. of } \\
\text { deaths }\end{array}$ & \\
\hline \multirow[t]{4}{*}{ Population 1} & \multirow[t]{2}{*}{ No } & Small & 28 & $12(42.9)$ & 0 & 0.00 \\
\hline & & Large & 30 & $14(46.7)$ & 1 & 0.07 \\
\hline & \multirow[t]{2}{*}{ Yes } & Small & 35 & 29 (82.8) & 13 & 0.45 \\
\hline & & Large & 30 & $25(83.3)$ & 6 & 0.24 \\
\hline \multirow[t]{5}{*}{ Population 2} & \multirow[t]{2}{*}{ No } & Small & 29 & $20(69.0)$ & 12 & 0.60 \\
\hline & & Large & 30 & $16(53.3)$ & 9 & 0.56 \\
\hline & \multirow[t]{3}{*}{ Yes } & Small & 20 & $20(100.0)$ & 15 & 0.75 \\
\hline & & Large & 30 & $29(96.7)$ & 19 & 0.66 \\
\hline & & Total & 232 & $165(71.1)$ & 75 & 0.46 \\
\hline
\end{tabular}
probability that a Bonamia-infected oyster would

\subsection{Survival analysis:} risk factors for time to oyster death

Oysters died at a consistent rate in both trials. The (1) 
Table 7. Generalised linear mixed model evaluating associations between potential risk factors and oyster status (subclinical or clinical bonamiosis) at the end of Trial 2 (83 d). Abbreviations as in Table 5. Statistical significance at $\mathrm{p} \leq 0.05$

\begin{tabular}{lcccccc|} 
Risk factor & $\beta$ & $\mathrm{SE}(\beta)$ & $\mathrm{p}$ & $\mathrm{OR}$ & $\mathrm{LCI}$ & $\mathrm{UCI}$ \\
\hline Population & 0.60 & 0.23 & 0.02 & 1.82 & 1.36 & 2.27 \\
Stressed & 0.65 & 0.49 & 0.21 & 1.92 & 0.95 & 2.89 \\
Oyster size & 0.14 & 0.53 & 0.79 & 1.15 & 0.11 & 2.19 \\
Stressed $\times$ population & -0.25 & 0.32 & 0.44 & 0.78 & 0.16 & 1.40 \\
Stressed $\times$ oyster size & -0.38 & 0.69 & 0.59 & 0.68 & -0.68 & 2.04 \\
Farm $\times$ oyster size & -0.08 & 0.33 & 0.80 & 0.92 & 0.28 & 1.56 \\
Stressed $\times$ population $\times$ & 0.16 & 0.44 & 0.72 & 1.17 & 0.31 & 2.04 \\
$\quad$ & & & & & & \\
\hline
\end{tabular}

purpose' for surveillance in a population assumed to be free of the disease. Application of the optimal epidemiological $C_{\mathrm{T}}$ cut-point resulted in a DSp and DSe of $92.2 \%$ (95\% PCI: $76.2 \%$, 99.8\%) and $93.5 \%$ (95\% PCI: $84.7 \%$, $99.1 \%)$, respectively. Contrary to previously held views, the heavily infected Australian native oysters in these trials demonstrated a systemic distribution of the $B$. exitiosa parasite when examined by histopathology. Risk factors for the death of Bonamia-infected oysters (i.e. subclinical to clinical bonamiosis) were reported based on 2 independent tank survive beyond a specified time (i.e. the estimated survival function) up to $56 \mathrm{~d}$ (Trial 1) was not significantly associated with increased water temperature, starvation or motion ( $\mathrm{p}>0.05)$. However, during Trial 2, when the estimated survival function was stratified by source Population (1 or 2) and application of stress (stressed/nonstressed), the death of Bonamia-infected oysters was influenced by both risk factors. Although on-site and prior to the trial start date there was apparently a lower mortality rate in Population 2 oysters, Bonamia-infected oysters sourced from this population died at 3.76 times the rate per unit time as Bonamia-infected Population 1 oysters during the tank trial (Fig. 5, Table 8). However, the association between clinical bonamiosis and stress was more complex, with a higher HR recorded in stressed Population 1 oysters, but the opposite effect in Population 2 oysters, particularly during the first 40-50 d of the trial period (Fig. 5). Oyster size did not have a significant influence on the HR $(p=0.35)$.

\section{DISCUSSION}

This paper describes the first published calculation of an optimal epidemiological qPCR $C_{\mathrm{T}}$ cut-point for Bonamia exitiosa in Australian native oysters $(\leq 34.5)$, in an area endemically infected with the parasite. This epidemiological cut-point is not 'fit for trials. In the first trial, factors that may stress an oyster, such as increased water temperature, starvation and oscillation, particularly when applied in combination,

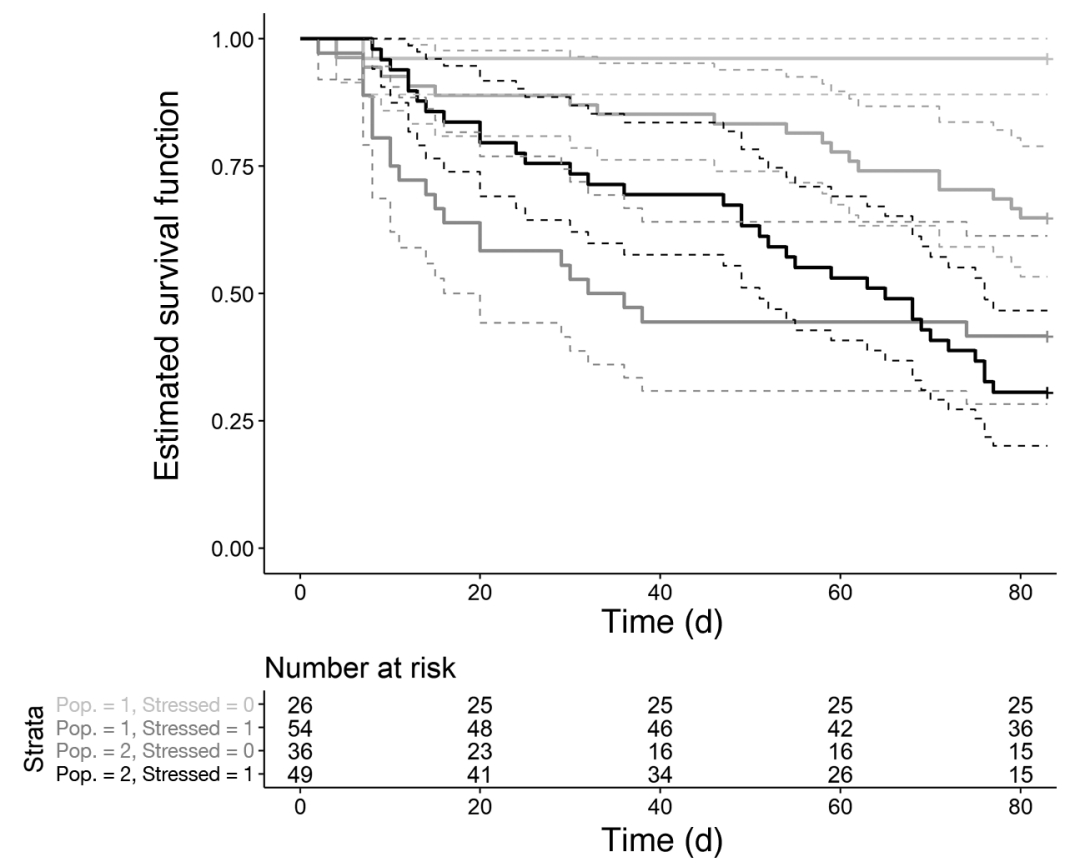

Fig. 5. Risk table and Kaplan-Meier plot with 95\% confidence bounds of survival of Bonamia-positive farmed native oysters from Victoria, Australia, stratified by source population and application of stress over the trial period (Trial 2: $83 \mathrm{~d}$ )

Table 8. Estimated ( $\beta$ ) from the Cox model of the hazard ratios (HR) of potential risk factors on the risk of death in Bonamia-positive farmed native oysters from Victoria, Australia ( $\mathrm{n}=165$ oysters). Abbreviations as in Table 5. Statistical significance at $\mathrm{p} \leq 0.05$

\begin{tabular}{|lcccccc|}
\hline Risk factor & $\beta$ & Robust SE $(\beta)$ & $p$ & HR & LCI & UCI \\
\hline Population & 1.32 & 0.47 & $<0.01$ & 3.76 & 1.49 & 9.49 \\
Stressed & 0.43 & 0.31 & 0.17 & 1.53 & 0.84 & 2.81 \\
Oyster size & -0.31 & 0.34 & 0.35 & 0.73 & 0.38 & 1.41 \\
\hline
\end{tabular}


increased the risk of oyster death due to clinical bonamiosis. In the second trial, the source of the oysters (Population) was significantly associated with clinical bonamiosis, but this relationship was influenced by the application of stress. Oysters from Population 2 (no history of clinical infection) died more rapidly and with a greater case fatality rate when stressed relative to Population 1 (previous mortalities attributed to $B$. exitiosa) oysters.

\subsection{Histopathological examination}

In line with previous work by Corbeil et al. (2009), B. exitiosa in Australian native oysters was observed most commonly and in the highest numbers within the haemocytes in the interstitium and the Leydig tissue of the digestive gland and palp and least commonly in the Leydig tissue surrounding the stomach. The interstitium and/or the digestive gland as a tissue type yielded $80 \%$ of the diagnoses of Bonamiapositive oysters. However, it is known that factors specific to the digestive gland, such as polysaccharides, cause PCR inhibition (Schrader et al. 2012). Ideally, to maximise the diagnostic sensitivity of the qPCR, protocols to counteract this inhibition are required with subsequent changes to recommendations in the OIE manual.

Contrary to the observations of other Australian workers (Corbeil et al. 2009, Buss et al. 2019), the pattern of infection with Bonamia did not vary from that seen in New Zealand and Europe (Hine 1991, Balouet et al. 1983). That is, oysters were systemically infected and did not uniquely display focal lesions with few parasites. It is likely that universal death in oysters related to this parasite is associated with systemic infection. In other parts of Australia there are limited records of oyster deaths due to infection with B. exitiosa. The difference in parasite is most likely a factor of infestation level. Presumably in the marine environment, a heavily infected, moribund oyster would either be rapidly preyed upon or tissue disintegration would prevent the ability to recover material that could illustrate the systemic nature of Bonamia infection. This systemically distributed pattern of infection was also seen during the $B$. exitiosa epizootic that resulted in high levels of mortalities in farmed native oysters in Port Phillip Bay in 2015 (J. Humphrey unpubl. data) despite rapid dilution of Bonamia infective particles in the marine environment. It is plausible that there is some form of genetic susceptibility to bonamiosis in Victorian Ostrea angasi; however, further work would be required to establish this.

\subsection{Calculation of DSe/DSp and an optimal epidemiological qPCR $C_{\mathrm{T}}$ value cut-point}

A PCR for B. exitiosa in O. chilensis has been previously validated with a DSe of $88 \%$ and a DSp of $36 \%$ relative to a 'gold standard' combination of histology and heart imprints (Diggles et al. 2003). Buss et al. (2019) recently compared histology, heart smear and the same qPCR as applied in this paper and found a lower DSe of qPCR $(69 \%)$, relative to histopathological examination (76\%), with the DSp equivalent at $93 \%$. This may have been because those authors calculated parameters based on an analytical cut-point (versus the epidemiological cut-point used in this paper) and that conditional dependence (covariance) between diagnostic tests was allowed, whilst we assumed conditional independence within the latent class analysis.

However, given the progression of the pathological process from initial infection with the parasite to recognisable tissue changes, it is reasonable to conclude that molecular detection of parasite presence is more sensitive than conventional histopathological examination, as shown by other researchers (Diggles et al. 2003, Balseiro et al. 2006, Marty et al. 2006, Ramilo et al. 2013) and this study. The currently applied gold standard for detecting $B$. exitiosa is histology (OIE 2019). However, given the much higher DSe of the qPCR (93.5\%) compared with histology $(50.8 \%)$ determined in this study and others, the convenience and speed of undertaking a PCR test and the ability to multiplex 2 or more Bonamia species in one test, we contend that the qPCR should replace histology as the OIE gold standard. It would also be beneficial to undertake diagnostic validation of species-specific molecular tests such as those developed by Ramilo et al. (2013).

The qPCR test provides a continuous outcome based on the $C_{\mathrm{T}}$, from which a binary outcome (positive or negative) must be determined (Caraguel et al. 2011). The higher a $C_{\mathrm{T}}$ value, the lower the concentration of target nucleic acids detected (and vice versa). Application of the optimal epidemiological $C_{\mathrm{T}}$ cutpoint in the present case resulted in a qPCR DSp and DSe of $92.2 \%$ (95\% PCI: 76.2\%, 99.8\%) and 93.5\% (95\% PCI: 84.7\%, 99.1\%), respectively. Histopathological examination had a slightly higher specificity (98.7\% ; 95\% PCI: 94.3\%, 99.9\%) but a relatively low diagnostic sensitivity $(50.8 \% ; 41.4 \%, 62.3 \%)$. This latter result seems plausible where oysters suffered from a lower level of infection making visualisation of $B$. exitiosa difficult, particularly if the stained section did not include any parasites. 
This is the first published calculation of an epidemiological qPCR cut-point $(\leq 34.5)$ for the diagnosis and management of enzootic $B$. exitiosa in farmed $O$. angasi. Establishing a binary cut-point in a diagnostic test with a continuous outcome is a required step in the pathway to test validation (OIE 2019). The first step in the validation pathway, however, is to select an appropriate test and validate it for a particular use as 'fit for purpose' (OIE 2019). In this instance, the application of an epidemiological cutpoint is appropriate for enzootic organisms where the farmer is attempting to minimize the economic impact of a pathogen through limiting the number of false positive and false negative diagnoses. This methodology has been increasingly applied in recent years to reduce the probability of, and costs associated with, misclassification related to terrestrial animal diseases (Vandenbussche et al. 2008, Mahmmod et al. 2013, Nielsen et al. 2015). The cut-point can equally be set for other purposes such as proof of freedom where the DSp (and hence positive predictive value) is prioritised (Caraguel et al. 2011). However, application of our epidemiological cut-point $(\leq 34.5)$ is not appropriate for purposes such as the detection of an exotic disease, as potential false positive or negative results can have significant ramifications. Where a test yields an unexpected positive result (possibly a false positive), further sampling and testing of the source population should be undertaken to increase the positive predictive value and determine the 'true' result. The return of false negatives in a truly diseased animal, however, presents a conundrum, and further testing to increase DSe may not be considered. The gravity of misclassification of a test result depends on the purposes for testing for example: national proof of freedom, an eradication campaign or estimating prevalence in an endemic area where the ramifications are much less.

Based on repeated annual negative testing for $B$. exitiosa, a lack of clinical evidence of bonamiosis and geographic distance from confirmed infected Populations 1 and 2, Population 3 was classified as a negative control population within Trial 2. However, 2 of the 50 oysters selected from that location had a qPCR cut-off of $<35.0$, indicating infection with $B$. exitiosa. The farm was classified as negative based on the same qPCR, so this result cannot be explained by a change in the diagnostic testing schedule. Either these oysters were false positives, which is possible considering the estimated specificity of the qPCR was $<100 \%$, or the oysters were truly infected. Although historically Population 3 has returned negative results, the movement of Bonamia across the bay is plausible, resulting in a low farm-level infection. Alternatively, as Bonamia is $2-3 \mu \mathrm{m}$ in diameter and the water used during the tank trials was only filtered down to $30 \mu \mathrm{m}$ and was from a known endemic area, it is possible that a small proportion of study oysters were infected via the water (Abollo et al. 2008).

\subsection{Risk factors for clinical bonamiosis: Trial 1}

Trial 1 examined the effect of a range of treatments on the survival of oysters infected with $B$. exitiosa, with the selection of risk factors determined by farmer consultation and previous results in the literature (van Banning 1991, Hine et al. 2002, Corbeil et al. 2009). The relationship between the risk of an oyster dying due to a single or combined risk factor was not straightforward. Where starvation was combined with cold and still water (i.e. no other risk factors applied), the increase in risk of death of $35 \%$ is biologically plausible. However, the apparent protective nature of starvation and hot water, for example, is more difficult to explain. When all risk factors of starvation, high temperature and increased motion (tumbling) were combined, there was a significant increase in the risk of death $(O R=3.47, p=0.02)$. As for many other disease processes, it is considered plausible that increased stress will result in an increased susceptibility of oysters to death due to $B$. exitiosa infection. Anecdotally, overcrowded cages, poor feed availability and other water quality issues have resulted in outbreaks of clinical bonamiosis in Port Phillip Bay, Victoria.

Applying a range of potential stressors to O. chilensis oysters, Hine et al. (2002) found that hyposalinity, exposing oysters to the air for $8 \mathrm{~h}$ and cold treatment resulted in the highest mortality rates. However, deaths in the hyposaline group were not believed to be related to $B$. exitiosa infection. In the same experiment it was found that the treatments that resulted in the highest overall prevalence of $B$. exitiosa (measured by histopathology) in both dead and surviving oysters were hot water, exposure to air and stir treatment (Hine et al. 2002). Although that work was undertaken in New Zealand with a different species of oyster and under different conditions, the results are comparable. Early observations on the oyster O. edulis in the Netherlands (van Banning 1991) also concluded that the prevalence and development of bonamiosis was related to stress and environmental factors.

In Trials 1 and 2, the potential effect of the tank environment on the observed mortality rates was 
estimated to be between 17 and $24 \%$. It is possible that there were other factors contributing to this rate, such as within-tank movement of ubiquitous pathogens (for example members of the genus Vibrio) in these stressed oysters or issues relating to the husbandry of the oysters and the tank location in the laboratory. The negative-control oysters were attended to first during inspections and were seen to be growing and feeding well. As such, they required less physical handling (a potential stressor) to ascertain whether they were still alive.

The mean ambient water temperature during Trial 1 was $18.2^{\circ} \mathrm{C}$, while the mean heated temperature was $22.9^{\circ} \mathrm{C}$. Temperatures recorded by loggers on the site in Port Phillip Bay have reached over $23^{\circ} \mathrm{C}$ but only for a few days at a time, so trial oysters were not routinely exposed to higher ambient temperatures and it was most likely that the sustained elevation in temperature during the tank trials was detrimental to the health of oysters. Port Phillip Bay is considered shallow with an average depth of $12 \mathrm{~m}$. With the effects of climate change on marine temperatures already apparent (Holbrook et al. 2019, Roberts et al. 2019), the detrimental effects of pathogens such as $B$. exitiosa in farmed oyster populations is likely to increase.

\subsection{Risk factors for clinical bonamiosis: Trial 2}

Trial 2 was designed to examine the findings of a field trial (authors' unpubl. data) where in situ smaller oysters from Population 1 had a higher mortality rate than larger oysters on the same site. This trial also evaluated the effects of stressors (e.g. heat and starvation) on the development of clinical bonamiosis from oysters sourced from both a clinically infected farm (Population 1) versus a subclinically infected farm (Population 2). Using the newly established epidemiological qPCR cut-point, 75 oysters were found to have died from clinical bonamiosis and 90 oysters were diagnosed with subclinical bonamiosis. Only 2 oysters died with a $C_{\mathrm{T}}$ value $>34.5$, indicating they died from a cause other than infection with Bonamia. From the variables applied, the only significant factor that emerged was the source, with Population 2 oysters having a 3.76 times greater daily hazard of death relative to Population 1, as well as a $82 \%$ higher risk of death during the overall trial period.

However, interestingly, the daily hazard of death by population was influenced by the application of stress (as starvation and increased water tempera- ture). As expected, the mortality rate was greatest in Population 1 oysters that were stressed. However, a similar effect was not replicated in Population 2. Therefore, the application of management practices to Population 1 that reduce the stress on oysters may reduce the prevalence of clinical bonamiosis. The influence of stress on Bonamia-infected oysters in Population 2 is more complicated, with unstressed oysters dying more quickly than stressed oysters over the trial period. If the Population 2 oysters have not developed the same level of resistance to clinical bonamiosis as Population 1 oysters, then the impact of management practices to solely limit stress may be less effective.

Physically, Populations 1 and 2 are located in different bays approximately $70 \mathrm{~km}$ apart and separated by a $10 \mathrm{~km}$ wide land peninsula. The stock at Population 1 were derived from farmed brood stock within Port Phillip Bay which were spawned at a local hatchery. The stock at Population 2 came from local wild broodstock that were spawned locally. Both sites have had a history of bonamiosis; however, Population 2 has not recorded clinical bonamiosis since stock re-establishment in recent years. During a major clinical outbreak of $B$. exitiosa in Population 1 in 2015 , it was estimated that up to $80 \%$ of the original stock was destroyed by the parasite. Extensive surveys to determine prevalence have not been undertaken at either site. The age classes of stock in both populations is uncertain, but it is possible that some of the oysters may have been as old as $5 \mathrm{yr}$. One hypothesis is that the stock from Populations 1 and 2 have quite distinct genetic profiles and that more recent strong selection pressures following clinical bonamiosis have resulted in surviving Population 1 oyster stock being less susceptible to developing clinical disease.

\section{CONCLUSIONS}

There are 4 main conclusions stemming from our work examining Bonamia exitiosa infection in farmed native Australian oysters Ostrea angasi: (1) there was a significant increase in the risk of oyster death during the tank trial when 3 proposed risk factors were combined: starvation, high temperature and increased motion (tumbling); (2) the odds of a Bonamia-positive oyster dying during the tank trial when all 3 stressors were applied (heat, starvation and tumbling) were almost $3 \frac{1}{2}$ times greater than for a positive oyster not subjected to those stressors. Further, supplying the oysters with warmer water alone increased the risk of 
a Bonamia-positive oyster dying by $58 \%$; (3) from From 2 separate forms of analysis in the second tank trial, oyster provenance was found to be a significant factor such that oysters from the farm that had previously not experienced clinical bonamiosis died at almost 4 times the rate of oysters from the farm that had experienced clinical bonamiosis; (4) the CSIRO qPCR yielded a relatively high DSe of $93.7 \%$ when compared with histopathology at $50.8 \%$. The specificity of both tests was very high at over $92.1 \%$. The optimal epidemiological cut-point for this assay was determined to be a $C_{\mathrm{T}}$ value of $\leq 34.5$ (as an indicator of infection with Bonamia exitiosa).

Acknowledgements. The authors acknowledge the Victorian farmers involved in this project and Mr. Ian Shurvell, who developed Fig. 1. The authors acknowledge the assistance of the Fisheries Research and Development Corporation (FRDC; Project Number 2015/001) in funding this project.

\section{LITERATURE CITED}

Abollo E, Ramilo A, Cases SM, Comesana P, Cao A, Carballal MJ, Villalba A (2008) First detection of the protozoan parasite Bonamia exitiosa (Haplospiridia) infecting flat oyster Ostrea edulis grown in European waters. Aquaculture 274:201-207

Balouet G, Poder M, Cahour A (1983) Haemocytic parasitosis: morphology and pathology of lesions in the French flat oyster, Ostrea edulis. Aquaculture 34:1-14

Balseiro P, Fernández Conchas R, Montes J, Gómez-León J, Novoa B, Figueras A (2006) Comparison of diagnostic techniques for the protozoan parasite Bonamia ostreae in the flat oyster Ostrea edulis. Aquaculture 261:1135-1143

Branscum AJ, Gardner IA, Johnson WO (2005) Estimation of diagnostic test sensitivity and specificity through Bayesian modeling. Prev Vet Med 68:145-163

Burns M, Valdivia H (2008) Modelling the limit of detection in real-time quantitative PCR. Eur Food Res Technol 226: 1513-1524

Buss JJ, Wiltshire KH, Prowse TAA, Harris JO, Deveny MR (2019) Bonamia in Ostrea angasi: diagnostic performance, field prevalence and intensity. J Fish Dis 42:63-74

Caraguel CGB, Stryhn H, Gagne N, Dohoo IR, Hammell KL (2011) Selection of a cutoff value for real-time polymerase chain reaction results to fit a diagnostic purpose: analytical and epidemiologic approaches. J Vet Diagn Invest 23:2-15

Corbeil S, Arzul I, Robert M, Berthe FCJ, Besnard-Cochennec N, Crane MSJ (2006) Molecular characterisation of an Australian isolate of Bonamia exitiosa. Dis Aquat Org 71:81-85

Corbeil S, Handlinger J, Crane MSJ (2009) Bonamiasis in Australian Ostrea angasi. Australia and New Zealand Standard Diagnostic Procedures. Department of Agriculture, Water and the Environment, Canberra

Diggles B, Cochennec N, Hine P (2003) Comparison of diagnostic techniques for Bonamia exitiosus from flat oysters Ostrea chilensis in New Zealand. Aquaculture 220: 145-156
Engelsma MY, Culloty SC, Lynch SA, Arzul I, Carnegie RB (2014) Bonamia parasites: a rapidly changing perspective on a genus of important mollusc pathogens. Dis Aquat Org 110:5-23

* Hall W, Wellner J (1980) Confidence bands for a survival curve from censored data. Biometrika 67:133-143

Handlinger JH, Rawin G, Wilson J, Johnston H, Condron R, O'Donoghue P, Phillips P (1999) Bonamiasis in Australia. In: Annual international conference and exposition of the World Aquaculture Society, 26 April-2 May 1999, Sydney. The Aquaculture Society, Sydney, p 310 (Abstract)

Hine P (1991) The annual pattern of infection by Bonamia sp. in New Zealand flat oysters, Tiostrea chilensis. Aquaculture 93:241-251

Hine P, Jones J (1994) Bonamia and other aquatic parasites of importance to New Zealand. NZ J Zool 21:49-56

* Hine P, Diggles B, Parsons M, Pringle A, Bull B (2002) The effects of stressors on the dynamics of Bonamia exitiosus Hine, Cochennec-Laureau \& Berthe, infections in flat oysters Ostrea chilensis (Philippi). J Fish Dis 25:545-554

*Holbrook NJ, Scannell HA, Sen Gupta A, Benthuysen JA and others (2019) A global assessment of marine heatwaves and their drivers. Nat Commun 10:2624

Johnston H (1992) Characterisation of Bonamia sp. in the Australian flat oyster Ostrea angasi. BSc (Hons) thesis, La Trobe University, Melbourne

* Lemeshow S, Hosmer D (1982) A review of goodness of fit statistics for use in the development of logistic regression models. Am J Epidemiol 115:92-106

Kahmmod YS, Toft N, Katholm J, Gronbaek C, Klaas I (2013) Estimation of test characteristics of real-time PCR and bacterial culture for diagnosis of subclinical intramammary infections with Streptococcus agalactiae in Danish dairy cattle in 2012 using latent class analysis. Prev Vet Med 109:264-270

Marty G, Bower S, Clarke K, Meyer G and others (2006) Histopathology and a real-time PCR assay for detection of Bonamia ostreae in Ostrea edulis cultured in western Canada. Aquaculture 261:33-42

Nell J (2001) The history of oyster farming in Australia. Mar Fish Rev 63:14-25

Nielsen PK, Petersen MB, Nielsen LR, Halasa T, Toft N (2015) Latent class analysis of bulk tank milk PCR and ELISA testing for herd level analysis of Mycoplasma bovis. Prev Vet Med 121:338-342

OIE (World Organisation for Animal Health) (2016) Quarterly animal disease report (Asia and Pacific region) JanuaryMarch 2016/1. https://rr-asia.oie.int/wp-content/uploads/ 2019/09/qaad-2016-1q.pdf (accessed 12 Sept 2019)

OIE (2019) Infection with Bonamia exitiosa. In: Manual of diagnostic tests for aquatic animals. OIE, Paris

R Core Team (2018) R: a language and environment for statistical computing. R Foundation for Statistical Computing, Vienna

* Ramilo A, Navas JI, Villalba A, Abollo E (2013) Speciesspecific diagnostic assays for Bonamia ostreae and B. exitiosa in European flat oyster Ostrea edulis: conventional, real-time and multiplex PCR. Dis Aquat Org 104:149-161

* Roberts SD, Van Ruth PD, Wilkinson C, Bastianello SS, Bansemer MS (2019) Marine heatwave, harmful algae blooms and an extensive fish kill event during 2013 in South Australia. Front Mar Sci 6:610

Schrader C, Schielke A, Ellerbroek L, Johne R (2012) PCR inhibitors - occurrence, properties and removal. J Appl Microbiol 113:1014-1026 
Spiegelhalter DJ, Best NG, Carlin BP, van der Linde A (2002) Bayesian measures of model complexity and fit. J R Stat Soc B 64:583-639

Stevenson M, Nunes T, Heyer C, Marshall J, Sanchez J and others (2019) epiR: tools for the analysis of epidemiological data. R package version 1.0-10 https://CRAN.R-project. org/package $=$ epiR

Thomas A, O'Hara B, Ligges U, Sturtz S (2006) Making BUGS open. R News 6:12-17

Toft N, Innocent G, Gettinby G, Reid S (2007) Assessing the convergence of Markov chain Monte Carlo methods: an

Editorial responsibility: Kimberly Reece,

Gloucester Point, Virginia, USA example from evaluation of diagnostic tests in absence of a gold standard. Prev Vet Med 79:244-256

* van Banning P (1991) Observations on bonamiasis in the stock of the European flat oyster, Ostrea edulis, in the Netherlands, with special reference to the recent developments in Lake Grevelingen. Aquaculture 93:205-211

* Vandenbussche F, Vanbinst T, Verheyden B, Van Dessel W and others (2008) Evaluation of antibody-ELISA and real-time RT-PCR for the diagnosis and profiling of bluetongue virus serotype 8 during the epidemic in Belgium in 2006. Vet Microbiol 129:15-27

Submitted: October 15, 2019; Accepted: June 15, 2020

Proofs received from author(s): August 1, 2020 